\title{
The Usefulness of the Incremental Load Repeated Standup Test in the Assessment of the Exercise Ca- pacity of Patients with Chronic Obstructive Pulmo- nary Disease
}

\author{
Jun Horie, PhD, $\mathrm{PT}^{1)^{*}}$, Kenichi Ito, PhD, $\mathrm{PT}^{2)}$, Shinichiro Hayashi, PhD, $\mathrm{MD}^{3)}$, \\ Hiromasa Fuji, MSc, PT ${ }^{4}$, Hideki Ishihara, MD ${ }^{4}$, Etsuo Horikawa, PhD ${ }^{3)}$ \\ 1) Department of Health Sciences, Kyoto Tachibana University: 34 Yamada-cho Oyake, Yamashina-ku, \\ Kyoto 607-8175, Japan. TEL: +81 75-571-1111, FAX: +81 75-574-4122 \\ 2) Department of Comprehensive Rehabilitation, Osaka Prefecture University \\ 3) Graduate School of Medicine, Saga University \\ 4) Department of Pulmonary Disease, Osaka Prefectural Medical Center for Respiratory and Allergic \\ Disease
}

\begin{abstract}
Purpose] Field walking tests are widely used to assess the exercise capacity of patients with chronic obstructive pulmonary disease (COPD). The present study aimed to examine whether or not the incremental load repeated standup test (IRST), a new field test which is easy to conduct, can substitute for existing field walking tests, the 6-minute walking distance (6MWD) and the incremental shuttle walking test (ISWT). [Methods] The cardiopulmonary exercise stress test (CEST), 6MWD, ISWT, and IRST were performed by18 Japanese male elderly patients with COPD. The IRST consists of repeated standups from a chair with incremental increases in the standup frequency. [Results] Single regression analysis using CEST-peak $\dot{\mathrm{VO}}_{2}$ as the dependent variable and the number of standups, walking distance, and walking distance, as independent variables gave the comparable regression formulae of: CEST-peak $\dot{\mathrm{V}} \mathrm{O}_{2}=0.12 \times$ number of standups in IRST +8.26 ; CEST-peak $\dot{\mathrm{VO}}_{2}=0.02 \times$ walking distance in the $6 \mathrm{MWD}+3.48$; and CEST-peak $\dot{\mathrm{VO}}_{2}=0.02 \times$ walking distance in the ISWT +6.48 , respectively. [Conclusion] The IRST is a potential substitute field test for the 6MWD and ISWT because it has comparable predictive ability and can be conducted in a very limited space.

Key words: Chronic obstructive pulmonary disease, Exercise, Physical fitness
\end{abstract}

(This article was submitted Oct. 11, 2012, and was accepted Nov. 20, 2012)

\section{INTRODUCTION}

Respiratory rehabilitation constitutes one of the three therapeutic interventions for elderly patients with chronic obstructive pulmonary disease (COPD), a chronically progressive disorder that extensively impairs activities of daily living (ADL) and quality of life (QOL) at the advanced stage. Various programs exist for improving exercise capacity, e.g., muscle-strengthening exercise and physical fitness exercise, and they have been proved to be effective at reducing the sensation of dyspnea and at improving patients' $\mathrm{ADL}$ and $\mathrm{QOL}^{1-3)}$. In recent years, falls by COPD patients resulting from their decreased exercise capacity have elicited concern ${ }^{4-8)}$. Therefore, emphasis has been placed on the importance of training for exercise capacity to maintain and improve ADL.

The assessment of exercise capacity is essential for objective appraisal of the status of patients with COPD. The assessment methods currently used in clinical settings in-

*To whom correspondence should be addressed.

E-mail: horie-j@tachibana-u.ac.jp clude the cardiopulmonary exercise stress test (CEST) and field walking tests. CEST can assess gas exchange and cardiovascular abilities in addition to evaluation of exercise capacity. However, the number of facilities capable of conducting CEST is still very limited, because the procedure requires both expensive devices and expert staff. On the other hand, field walking tests such as the 6-minute walking distance $(6 \mathrm{MWD})^{9,10)}$ and the incremental shuttle walking test (ISWT) are assessment methods that are widely used throughout the world ${ }^{11)}$, because their procedures require no expensive instruments and are easy to perform when sufficient space is available. However, field walking tests are not suitable for patients with impaired walking ability and pose problems in the management of risks, e.g., fall. Many COPD patients are elderly with impaired walking ability which effectively excludes them from performing these tests in clinical settings.

In the present study, instead of the conventional movement activity, walking, we used repeated standups from a chair with incremental increases in frequency, as it requires no walking for assessment and allows chairside physical intervention for management of risks. The purpose of this study was to investigate whether the IRST is comparable to 
the 6MWD and IRST in predictive ability by comparing and evaluating the relationships between CEST, 6MWD, ISWT, and the incremental load repeated standup test (IRST).

\section{SUBJECTS AND METHODS}

A pilot study was conducted with 10 healthy volunteers prior to the present study. The reliability was good as evidenced by intraclass correlation coefficients (r) of 0.97 and 0.84 for number of standups and IRST-peak $\dot{\mathrm{VO}}_{2}$, respectively.

The present study was conducted with 18 Japanese elderly male patients with stable COPD (mean age: 71.1 years) who were undergoing respiratory rehabilitation at hospitals specialized in the treatment of respiratory diseases. Demographic and clinical characteristics of the subjects are shown in Table 1. The subjects did not use an oxygen supply or short-acting bronchodilators, but they were allowed to use long-acting bronchodilators. The following patients were excluded: those who presented impaired walking due to pain or other disorders; those who had serious complications other than respiratory disease; those who did not comprehend the objective and outline of the study; and those who did not provide written informed consent. The present study was conducted after receiving approval from the ethical review board of Osaka Prefectural Medical Center for Respiratory and Allergic Diseases.

The exercise capacity of individual patients was assessed by randomly conducting the 6MWD, ISWT, CEST, and IRST on different days, with one test conducted per day. In all these tests, exercise capacity was assessed without supplementary oxygen to ensure the same testing conditions.

For the 6MWD, subjects were instructed to walk for 6 minutes at their maximum walking speed up and down a $35-\mathrm{m}$ corridor of the hospital. The walking distance achieved was entered into the prediction formula for peak $\dot{\mathrm{V}}_{2}(=0.006 \times[$ walking distance $/ 0.348]+3.338)$ to calculate the predicted value for peak $\mathrm{V}_{2}$ for the $6 \mathrm{MWD}$ (6MWD-peak $\dot{\mathrm{VO}}_{2}$ predicted $)^{9}, 10$ ).

For the ISWT, subjects were instructed to walk in time with beeps emitted by a compact disk player. The walking distance achieved was entered into the prediction formula for peak $\dot{\mathrm{VO}}_{2}(=0.025 \times$ walking distance +4.19$)$ to calculate the predicted value for peak $\dot{\mathrm{VO}}_{2}$ in the ISWT (ISWTpeak $\dot{\mathrm{VO}}_{2}$ predicted) ${ }^{11)}$.

For the CEST, a bicycle ergometer (RM300i, Minato,

Table 1. Demographic and clinical characteristics of patients with chronic obstructive pulmonary disease whose functional exercise capacity was assessed by CEST, 6MWD, ISWT, and IRST

\begin{tabular}{|c|c|c|}
\hline Variable & & $\begin{array}{l}\text { Correlation } \\
\text { coefficient }\end{array}$ \\
\hline Male gender, $\mathrm{n}$ & 18 & \\
\hline Age, yrs; mean \pm SD (range) & $71.1 \pm 8.7(57-87)$ & \\
\hline MRC scale & $2: 9,3: 9$ & \\
\hline GOLD stage ${ }^{\#}$ & I: 2, II: 3 , III: 10, IV: 3 & \\
\hline $\mathrm{pH} ;$ mean $\pm \mathrm{SD}$ (range) & $7.41 \pm 0.03(7.36-7.47)$ & \\
\hline $\mathrm{PaCO}_{2}$, torr & $42.8 \pm 4.7(34.8-50.3)$ & \\
\hline $\mathrm{PaO}_{2}$, torr & $81.1 \pm 14.1(56.9-102.4)$ & \\
\hline FVC $\%$ predicted, $\%$ & $70.2 \pm 17.8(37.6-108.8)$ & 0.34 \\
\hline $\mathrm{FEV}_{1} / \mathrm{FVC}$ ratio, $\%$ & $51.7 \pm 13.4(20.8-69.0)$ & 0.44 \\
\hline $\mathrm{FEV}_{1}$ predicted, $\%$ & $45.2 \pm 20.3(27.3-92.7)$ & $0.50 *$ \\
\hline Walking distance in 6MWT, $\mathrm{m}$ & $481.4 \pm 81.6(380-630)$ & $0.66^{*}$ \\
\hline Walking distance in ISWT, m & $461.1 \pm 124.9(330-780)$ & $0.58 *$ \\
\hline $\mathrm{MVV}, \mathrm{L} / \mathrm{min}$ & $51.3 \pm 20.9(23.2-88.5)$ & $0.68 * *$ \\
\hline $\mathrm{MIP}, \mathrm{cmH}_{2} \mathrm{O}$ & $61.9 \pm 24.6(29.7-96.2)$ & 0.06 \\
\hline $\mathrm{MEP}, \mathrm{cmH}_{2} \mathrm{O}$ & $80.0 \pm 23.2(42.2-110.0)$ & 0.30 \\
\hline LE muscle mass, kg & $17.1 \pm 3.8(12.7-16.4)$ & -0.18 \\
\hline NRADLQ total, point & $94.6 \pm 8.1(66-100)$ & 0.18 \\
\hline SGRQ total, point & $39.5 \pm 11.0(24.4-63.7)$ & -0.23 \\
\hline CEST-peak $\dot{\mathrm{VO}}_{2}$ & $14.1 \pm 3.0(11.4-18.6)$ & $0.66^{* *}$ \\
\hline IRST-peak $\dot{\mathrm{VO}}_{2}$ & $14.6 \pm 3.2(9.1-18.9)$ & $0.62 *$ \\
\hline
\end{tabular}

Values are expressed as mean \pm SD except \#,numbers of subjects. Numerals in parentheses denote the range. Correlation coefficients indicate Pearson's product-moment correlation coefficients. $*: \mathrm{p}<0.05, * *: \mathrm{p}<0.01$

MRC: medical research council; GOLD: global initiative for chronic obstructive lung disease; FVC: forced vital capacity; $\mathrm{FEV}_{1}$ : 1 second forced expiratory volume; 6MWD: 6 minute walking distance; MVV: maximum voluntary ventilation; MIP: maximum inspiratory pressure; MEP: maximum expiratory pressure; LE: lower extremity; NRADLQ: Nagasaki Respiratory ADL questionnaire; SGRQ: St. George's Respiratory Questionnaire; ISWT: incremental shuttle walking test; CEST: cardiopulmonary exercise stress test; $\dot{\mathrm{VO}}_{2}$ : oxygen uptake; IRST: incremental load repeated standup test 
Osaka, Japan) was used to induce exercise stress, and exhaled gas was analyzed according to the breath-by-breath method. Subjects took a 3-minute rest, performed 1-minute warm-up and then performed a 10-watt/minute linear incremental stress (ramp stress) test up to the symptom-limited peak exercise stress, that was defined as when the patient was considered to have reached his physical limits based on subjective symptoms; heart rate (HR) was $\geq 85 \%$ of the predicted maximum heart rate (220 - age); oxygen saturation was $\leq 85 \%$; a physician judged a patient was unfit to continue with the exercise based on electrocardiograms; or the physician found it difficult to continue with the exercise. The test was terminated at the time of symptom-limited peak exercise stress when the following variables were measured: $\dot{\mathrm{VO}}_{2}$ (CEST-peak $\dot{\mathrm{V}} \mathrm{O}_{2}$ ); HR (CEST-peak HR); $\dot{\mathrm{VO}}_{2} / \mathrm{HR}\left(\mathrm{O}_{2}\right.$ pulse) (CEST-peak $\mathrm{O}_{2}$ pulse); minute ventilation ( $\dot{\mathrm{V} E})(\mathrm{CEST}-$ peak $\dot{\mathrm{V} E})$; VE/maximal voluntary ventila-

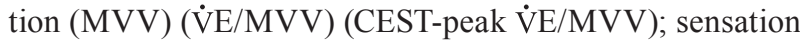
of dyspnea (D-BS) (CEST-peak D-BS); sensation of fatigue in the lower extremities (LE-BS) (CEST-peak LE-BS); oxygen equivalent $\left(\dot{\mathrm{V} E} / \dot{\mathrm{VO}}_{2}\right)$ at the aerobic threshold (CEST-AT $\left.\dot{\mathrm{V} E} / \mathrm{V}_{2}\right)$; and carbon dioxide equivalent ( $\dot{\mathrm{V} E} /$ carbon dioxide output $\left.\left[\dot{\mathrm{V}} \mathrm{CO}_{2}\right]\right)$ at the aerobic threshold (CEST-AT $\dot{\mathrm{V} E} /$ $\dot{\mathrm{V}} \mathrm{CO}_{2}$ ).

For the IRST, exhaled gas was analyzed according to the same method as described for CEST. The height of the chair was adjusted for each subject to obtain an angle of 100 degrees of flexion in the knee joints. Subjects were instructed to hold both hands crossed on the chest and to completely keep the back in contact with the backrest of the chair. For the standup and standing positions, subjects were instructed to keep the knee joints in the position of complete extension. For the control of stress, an electronic metronome was used to regulate 20 standups per minute at the onset of stress. Subsequently, stress was increased up to symptomlimited peak exercise stress, which was defined as three or more failures to keep up with the metronome beeps in addition to the conditions described for CEST, according to the multiple stage incremental stress method by which 10 standups per minute were gradually added. The test was terminated at the time of symptom-limited peak exercise stress, when the following variables were measured: number of standups; $\dot{\mathrm{V}} \mathrm{O}_{2}$ (IRST-peak $\dot{\mathrm{V}} \mathrm{O}_{2}$ ); HR (IRSTpeak HR); $\mathrm{O}_{2}$ pulse (IRST-peak $\mathrm{O}_{2}$ pulse); $\dot{\mathrm{V} E}$ (IRST-peak $\dot{V} E$ ); $\dot{V E} / M V V$ (IRST-peak VंE/MVV); D-BS (IRST-peak D-BS); LE-BS (IRST-peak LE-BS); $\dot{\mathrm{VE}} / \dot{\mathrm{VO}}_{2}$ at the aerobic threshold (IRST-AT $\dot{\mathrm{V} E} / \dot{\mathrm{V}} \mathrm{O}_{2}$ ); and $\dot{\mathrm{VE}} / \dot{\mathrm{V}} \mathrm{CO}_{2}$ at the aerobic threshold (IRST-AT $\dot{\mathrm{V} E} / \dot{\mathrm{V}} \mathrm{CO}_{2}$ ).

For other measurements, a spirometer (Autospiro AS502, Minato) was used to measure MVV twice, and the best value was adopted. A body composition meter (Body Planner EX/P DF830, Yamato-Scale, Hyogo, Japan) was used to measure body fat percentage, muscle mass ratio, and lower extremity muscle mass ratio. The Nagasaki Respiratory ADL Questionnaire (NRADLQ; including 11 items) and St. George's Respiratory Questionnaire (SGRQ; including 50 items) were used to assess ADL and health-related QOL, respectively.

After conducting of repeated measures analysis of vari- ance, Scheffé's multiple comparison test was conducted as a post hoc test to compare 6MWD-peak $\dot{\mathrm{VO}}_{2}$ predicted, ISWT-peak $\dot{\mathrm{V}} \mathrm{O}_{2}$ predicted, CEST-peak $\dot{\mathrm{V}} \mathrm{O}_{2}$, and IRSTpeak $\dot{\mathrm{V}} \mathrm{O}_{2}$. Furthermore, the paired t-test was performed to compare the exhaled gas analysis values of CEST and IRST. To predict peak $\mathrm{VO}_{2}$ based on the number of standups in the IRST, single regression analysis was performed using CEST-peak $\dot{\mathrm{VO}}_{2}$ as the dependent variable and the number of standups in the IRST, walking distance in the 6MWD, and walking distance in the ISWT as independent variables. Measurement values are expressed as mean $\pm \mathrm{SD}$. An alpha level of $<0.05$ was chosen for the rejection of the null hypothesis, and a value of $\mathrm{p}<0.05$ was considered statistically significant. The statistical software used was the SPSS Software version 17 (SPSS Japan, Tokyo, Japan).

\section{RESULTS}

Peak $\dot{\mathrm{V}} \mathrm{O}_{2}(\mathrm{~mL} / \mathrm{min} / \mathrm{kg})$ were as follows: 6MWD-peak $\dot{\mathrm{V}} \mathrm{O}_{2}$ predicted, $12.9 \pm 1.6$; ISWT-peak $\dot{\mathrm{V}} \mathrm{O}_{2}$ predicted, 15.7 \pm 3.1 ; CEST-peak $\dot{\mathrm{VO}}_{2}$ predicted, $14.1 \pm 3.0$; and IRST-peak $\dot{\mathrm{VO}}_{2}$ predicted, $14.6 \pm 3.2$. Comparison of the peak oxygen uptake values according to differences in the assessment methods of exercise capacity revealed that ISWT-peak $\dot{\mathrm{VO}}_{2}$ predicted was significantly higher $(\mathrm{p}<0.01)$ than 6MWDpeak $\dot{\mathrm{VO}}_{2}$ predicted and that IRST-peak $\dot{\mathrm{VO}}_{2}$ predicted was significantly higher $(\mathrm{p}<0.05)$ than $6 \mathrm{MWD}$-peak $\dot{\mathrm{V}} \mathrm{O}_{2}$ predicted. However, no significant differences were found for the other variables.

The number of standups showed significant correlations with MVV $(\mathrm{r}=0.68, \mathrm{p}<0.01)$, percent $\mathrm{FEV}_{1}(\mathrm{r}=0.50, \mathrm{p} \leq$ $0.05), 6 \mathrm{MWD}(\mathrm{r}=0.66, \mathrm{p}<0.05)$, and walking distance in the ISWT $(r=0.58, \mathrm{p}<0.05)$ (Table 1).

A comparison of the results of the exhaled gas analysis at peak exercise stress between CEST and IRST revealed that CEST showed significantly high $\dot{\mathrm{V} E}(\mathrm{p}<0.05)$, and $\dot{\mathrm{V} E} / \mathrm{MVV}(\mathrm{p}<0.05)$ and significantly low $\mathrm{O}_{2}$ pulse $(\mathrm{p}<$ $0.01)$. Furthermore, a comparison of variables at the anaerobic threshold between CEST and IRST revealed that CEST showed significantly high $\dot{\mathrm{V} E} / \dot{\mathrm{V}} \mathrm{O}_{2}(\mathrm{p}<0.01)$ and $\dot{\mathrm{V} E} / \dot{\mathrm{V} C O}{ }_{2}$ $(\mathrm{p}<0.05)($ Table 2).

Single regression analysis using CEST-peak $\dot{\mathrm{VO}}_{2}$ as the dependent variable and the number of standups in the IRST as the independent variable gave a regression formula of CEST-peak $\dot{\mathrm{VO}}_{2}=0.12 \times$ number of standups in IRST + $8.26\left(\mathrm{R}^{2}=0.44, \mathrm{p}<0.01\right)$, which was comparable to the $6 \mathrm{MWD}\left(\mathrm{R}^{2}=0.36, \mathrm{p}<0.01\right)$ and the ISWT $\left(\mathrm{R}^{2}=0.48, \mathrm{p}\right.$ $<0.01)$.

\section{DISCUSSION}

The present study investigated whether or not IRST, a test which can be performed in a very limited space, can substitute for existing field walking tests, the 6MWD and ISWT.

To verify whether or not peak $\dot{\mathrm{VO}}_{2}$ is predicted, single regression analysis was conducted using CEST peak $\dot{\mathrm{VO}}_{2}$ as the dependent variable and the number of standups in the IRST as the independent variable. To compare the predictive ability of IRST with existing field walking tests, single 
Table 2. Measurement values at peak between the incremental load repeated standup test and the cardiopulmonary exercise stress test

\begin{tabular}{|c|c|c|}
\hline Variable & CEST & IRST \\
\hline Number of standups & & $47.0 \pm 17.0$ \\
\hline$\dot{\mathrm{V}} \mathrm{O}_{2}, \mathrm{~mL} / \mathrm{min} / \mathrm{kg}$ & $14.1 \pm 3.0$ & $14.6 \pm 3.2$ \\
\hline $\mathrm{HR}, \mathrm{bpm}$ & $122.5 \pm 13.1$ & $118.1 \pm 17.4$ \\
\hline$\dot{\mathrm{V}} \mathrm{E} / \mathrm{V}_{2}{ }_{2}^{\#}, \mathrm{~mL} / \mathrm{mL} / \mathrm{min}$ & $48.5 \pm 7.4$ & $42.8 \pm 9.0 * *$ \\
\hline$\dot{\mathrm{VE}} / \dot{\mathrm{V} C O}{ }_{2}^{\#}, \mathrm{~mL} / \mathrm{mL} / \mathrm{min}$ & $46.4 \pm 6.4$ & $43.4 \pm 8.0^{*}$ \\
\hline$\dot{\mathrm{VE}}, \mathrm{mL}$ & $38.8 \pm 13.9$ & $35.8 \pm 11.6^{*}$ \\
\hline$\dot{\mathrm{VE}} / \mathrm{MVV}, \%$ & $80.7 \pm 25.8$ & $76 \pm 23.0^{*}$ \\
\hline $\mathrm{O}_{2}$ pulse, $\mathrm{mL} /$ beat & $6.7 \pm 2.2$ & $7.1 \pm 2.1^{* *}$ \\
\hline$\Delta \mathrm{SpO}_{2,} \%$ & $5.8 \pm 3.6$ & $7.0 \pm 4.7$ \\
\hline Borg scale, dyspnea & $5.6 \pm 3.2$ & $5.6 \pm 2.4$ \\
\hline Borg scale, LE fatigue & $5.5 \pm 3.4$ & $4.6 \pm 2.8$ \\
\hline
\end{tabular}

\#: Measurement value at the threshold for anaerobic metabolism. Values are expressed as mean $\pm \mathrm{SD}$

$*: \mathrm{p}<0.05, * *: \mathrm{p}<0.01$

CEST: cardiopulmonary exercise stress test; IRST: incremental load repeated standup test; $\dot{\mathrm{VO}}_{2}$ : oxygen uptake; LE: lower extremity; HR: heart rate; $\dot{\mathrm{V} E}$ : minimum ventilation; $\dot{\mathrm{V} C \mathrm{CO}_{2}}$ : carbon dioxide output; $\mathrm{MVV}$ : maximal voluntary ventilation; $\mathrm{O}_{2}$ pulse: $\dot{\mathrm{VO}}_{2} / \mathrm{HR}$; LE: lower extremity

regression analysis was using conducted the walking distances of 6MWD and ISWT as independent variables. The correlation coefficients of IRST, 6MWD, and ISWT were calculated to be $0.44,0.36$, and 0.48 , respectively. Although these coefficients cannot be considered to imply high precision in predicting peak $\mathrm{V}_{2}$, they suggest the number of standups in IRST has a predictive ability comparable to the walking distances of the 6MWD and ISWT.

Comparisons of the measured values of peak $\mathrm{VO}_{2}$ in CEST and IRST, as well as of the predicted values of peak $\dot{\mathrm{V}} \mathrm{O}_{2}$ based on walking distances of the 6MWD and ISWT revealed no significant difference between the 6MWD and ISWT, or between the 6MWD and IRST. The 6MWD provides low estimates of peak $\dot{\mathrm{VO}}_{2}{ }^{12-15}$. On the other hand, IRST showed no significant difference from the predicted ISWT-peak $\mathrm{VO}_{2}$, a relatively accurate estimate of peak $\dot{\mathrm{V}} \mathrm{O}_{2}$, or from CEST-peak $\dot{\mathrm{VO}}_{2}$, a measured value of peak $\dot{\mathrm{V}} \mathrm{O}_{2}$. Therefore, these results suggest IRST is capable of estimating peak $\mathrm{VO}_{2}$ nearly as precisely as ISWT and CEST. A possible explanation for why IRST provides slightly higher values of peak $\dot{\mathrm{VO}}_{2}$ than those of CEST is that the activity of trunk muscles increases in repeated standups more than in cycling on a bicycle ergometer ${ }^{16-18)}$; therefore, subjects performed a motion better resembling whole body motion (walking) in IRST than in $\mathrm{CEST}^{19}{ }^{20)}$. A previous study indicated that peak $\mathrm{V}_{2}$ estimated using a bicycle ergometer was 89 to $95 \%$ of peak oxygen uptake measured during exercise on a treadmill. The results of the present study corroborate these results since CEST-peak $\dot{\mathrm{V}} \mathrm{O}_{2}$ was approximately $96 \%$ of IRST-peak $\dot{\mathrm{V}} \mathrm{O}_{2}$. Patients with COPD are frequently instructed to walk as an exercise in exercise prescription. If IRST provides a motion resembling walking, IRST would enable not only simple assessment of the exercise capacity of patients with COPD, but also provide informative data for the determination of exercise prescrip- tion.

Regarding associations between the number of standups and measurement items, IRST showed significant correlations with 6MWD and ISWT, that are currently widely used conducted elsewhere as methods to assess exercise capacity. This suggests that IRST is an appropriate method for assessing exercise capacity. Furthermore, a significant correlation was found between $\mathrm{FEV}_{1}$ pred and MVV that is specified by $\mathrm{FEV}_{1}$. This suggests that IRST results also correlate with the severity of airway obstruction. Many previous studies in patients of COPD have reported an association between the severity of airway obstruction and exercise capacity $^{21,22)}$. We suggest IRST could be used to assess the exercise capacity of patients with COPD since it involves no theoretical contradiction regarding the aspect of airway obstruction.

Regarding the comparison of exhaled gas analysis values, a detailed procedure used to assess exercise capacity, there were no significant differences in peak $\dot{\mathrm{VO}}_{2}$ and peak HR between CEST and IRST based on subjective symptoms of patients (sensation of dyspnea and sensation of fatigue in the lower extremities). These results suggest that IRST is capable of measuring symptom limits at loads equivalent to those used in CEST.

Ventilation efficacy, $\dot{\mathrm{V} E} / \mathrm{V}_{2}$ and carbon dioxide equivalent $\left(\dot{\mathrm{V} E} / \dot{\mathrm{V}} \mathrm{CO}_{2}\right)$, and ventilatory reserve, $\dot{\mathrm{V} E} / \mathrm{MVV}$, were significantly lower in IRST, suggesting less stress on ventilatory capacity. On the other hand, cardiovascular capacity, $\mathrm{O}_{2}$ pulse was significantly higher. Therefore, IRST contrarily inflicted greater stress on cardiovascular capacity and oxygenation capacity. We assume that exercise duration factor is involved in this result. Usually, the best duration of exercise is considered to be 8 to 12 minutes in $\mathrm{CEST}^{23}$, 24). In the present study, however, the average duration of exercise in IRST was approximately 3 minutes. Thus, the 
lower stress on ventilatory capacity was the result of exercise being terminated before the lungs became overinflated, and that the higher stresses on cardiovascular capacity and oxygenation capacity resulted from the because the duration of the exercise being short.

The number of subjects in our study was limited $(\mathrm{n}=18)$. However, a spirometer was used to ensure the collection of precise data. Therefore, statistical analyses were performed based on highly objective data. To the best of our knowledge, this is the first study that has attempted to asses the exercise capacity of patients with COPD in a clinical setting by performing a simple and less stressful activity, repeated standups from a chair.

The results of our study suggest the potential application of IRST as an appropriate abbreviated method for measuring the exercise capacity of patients with COPD. Nevertheless, IRST does not exclude the use of conventional field walking tests. The validation of IRST was performed in the present study to solve the clinical issue of there being many patients who are difficult to assess by these conventional tests in clinical settings. The chairside physical intervention of IRST permits the objective assessment of exercise capacity, exercise prescription, and treatment efficacy validation for patients with COPD who are incapable of performing a field walking test or are excluded from doing so for safety reasons. IRST can be performed in a very limited space making it possible to validate the long-term efficacy of a given exercise prescription, one of challenges which needs to be ddressed in respiratory rehabilitation ${ }^{25-27)}$.

\section{ACKNOWLEDGEMENT}

The authors thank Dr. Satoshi Sakima for his critical review of the manuscript.

\section{REFERENCES}

1) American College of Chest Physicians and the American Association of Cardiovascular and Pulmonary Rehabilitation Pulmonary rehabilitation: joint ACCP/AACVPR evidence-based guidelines. ACCP/AACVPR Pulmonary Rehabilitation Guidelines Panel. American College of Chest Physicians. American Association of Cardiovascular and Pulmonary Rehabilitation. Chest, 1997, 112: 1363-1396. [Medline] [CrossRef]

2) American Thoracic Society: Dyspnea. Mechanisms, assessment, and management: a consensus statement. American Thoracic Society. Am J Respir Crit Care Med, 1999, 159: 321-340. [Medline]

3) Casaburi R, Kukafka D, Cooper CB, et al.: Improvement in exercise tolerance with the combination of tiotropium and pulmonary rehabilitation in patients with COPD. Chest, 2005, 127: 809-817. [Medline] [CrossRef]

4) Hellström K, Vahlberg B, Urell C, et al.: Fear of falling, fall-related selfefficacy, anxiety and depression in individuals with chronic obstructive pulmonary disease. Clin Rehabil, 2009, 23: 1136-1144. [Medline] [CrossRef]

5) Roig M, Eng JJ, Road JD, et al.: Falls in patients with chronic obstructive pulmonary disease: a call for further research. Respir Med, 2009, 103 1257-1269. [Medline] [CrossRef]

6) Lawlor DA, Patel R, Ebrahim S: Association between falls in elderly women and chronic diseases and drug use: cross sectional study. BMJ, 2003,
327: 712-717. [Medline] [CrossRef]

7) Smith MD, Chang AT, Seale HE, et al.: Balance is impaired in people with chronic obstructive pulmonary disease. Gait Posture, 2010, 31: 456-460. [Medline] [CrossRef]

8) Beauchamp MK, Hill K, Goldstein RS, et al.: Impairments in balance discriminate fallers from non-fallers in COPD. Respir Med, 2009, 103: 1885-1891. [Medline] [CrossRef]

9) Sciurba F, Criner GJ, Lee SM, et al. National Emphysema Treatment Trial Research Group: Six-minute walk distance in chronic obstructive pulmonary disease. Am J Respir Crit Care Med, 2003, 167: 1522-1527. [Medline] [CrossRef]

10) Guyatt GH, Sullivan MJ, Thompson PJ, et al.: The 6-minute walk: a new measure of exercise capacity in patients with chronic heart failure. Can Med Assoc J, 1985, 132: 919-923. [Medline]

11) Singh SJ, Morgan MD, Scott S, et al.: Development of a shuttle walking test of disability in patients with chronic airways obstruction. Thorax, 1992, 47: 1019-1024. [Medline] [CrossRef]

12) Turner SE, Eastwood PR, Cecins NM, et al.: Physiologic responses to incremental and self-paced exercise in COPD; a comparison of three tests. Chest, 2004, 126: 668-670. [CrossRef]

13) Luxton N, Alison JA, Wu J, et al.: Relationship between field walking tests and incremental cycle ergometry in COPD. Respirology, 2008, 13: 856-862. [Medline] [CrossRef]

14) Hodgev VA, Aliman OI, Marinov BI, et al.: Cardiovascular and dyspnea response to six-minute and shuttle walk tests in COPD patients. Folia Med (Plovdiv), 2003, 45: 26-33. [Medline]

15) Troosters T, Vilaro J, Rabinovich R, et al.: Physiological responses to the 6-min walk test in patients with chronic obstructive pulmonary disease. Eur Respir J, 2002, 20: 564-569. [Medline] [CrossRef]

16) Paquet N, Malouin F, Richards CL: Hip-spine movement interaction and muscle activation patterns during sagital trunk movements in low back pain patients. Spin, 1994, 19: 596-603. [CrossRef]

17) Farfan HF: Muscular mechanism of the lumber spine and the position of power and efficiency. Orthop Clin North Am, 1975, 6: 135-144. [Medline]

18) Nouwen A, Van Akkerveeken PF, Versloot JM: Patterns of muscular activity during movement in patients with chronic low back pain. Spine, 1987, 12: 777-782. [Medline] [CrossRef]

19) Wyndham CH, Strydom NB, Leary WP, et al.: Studies of the maximum capacity of men for physical effort. 3 . The effects on the maximum oxygen intake of young males of a regime of regular exercise and an adequate diet. Arbeitsphysiologie, 1966, 22: 285-289.

20) Davis JA, Kasch FW: Aerobic and anaerobic differences between maximal running and cycling in middle-aged males. Aust J Sports Med, 1975, 7: $81-84$

21) Pinto-Plata VM, Celli-Cruz RA, Vassaux C, et al.: Differences in cardiopulmonary exercise test results by American Thoracic Society/European Respiratory Society-Global Initiative for Chronic Obstructive Lung Disease stage categories and gender. Chest, 2007, 132: 1204-1211. [Medline] [CrossRef]

22) Eisner MD, Iribarren C, Yelin EH, et al.: Pulmonary function and the risk of functional limitation in chronic obstructive pulmonary disease. Am J Epidemiol, 2008, 167: 1090-1101. [Medline] [CrossRef]

23) American Thoracic Society and American College of Chest Physicians: American Thoracic Society/American College of Chest Physicians Statement on Cardiopulmonary exercise testing. Am J Respir Crit Care Med, 2003, 167: 211-277. [Medline] [CrossRef]

24) Buchfuhrer MJ, Hansen JE, Robinson TE, et al.: Optimizing the exercise protocol for cardiopulmonary assessment. J Appl Physiol, 1983, 55: 15581564. [Medline]

25) Güell R, Casa P, Belda J, et al.: Long-term effects of outpatient rehabilitation of COPD: a randomized trial. Chest, 2000, 117: 976-983. [Medline] [CrossRef]

26) Ries AL, Kaplan RM, Myers R, et al.: Maintenance after pulmonary rehabilitation in chronic lung disease: a randomized trial. Am J Respir Crit Care Med, 2003, 167: 880-888. [Medline] [CrossRef]

27) Foglio K, Bianchi L, Bruletti G, et al.: Seven-year time course of lung function, symptoms, health-related quality of life, and exercise tolerance in COPD patients undergoing pulmonary rehabilitation programs. Respir Med, 2007, 101: 1961-1970. [Medline] [CrossRef] 